\title{
Patient's Comfort and Technical Quality Exams at 1.5 and 3.0 T Magnetic Resonance Imaging
}

\section{Siniša Vujmilović1, Saša Vujnović1, Violeta Kovačević-Dragosavljević1, Zoran Vujković ${ }^{\text {, }}$ Davorka Katana², Dragana Grujić-Vujmilovićc ${ }^{3}$}

${ }^{1}$ Institute of Clinical Radiology, University Clinical Centre of the Republic of Srpska, Bosnia and Herzegovina, Banjaluka, Bosnia and Herzegovina

${ }^{2}$ Clinic of Neurology, University Clinical Centre of the Republic of Srpska, Bosnia and Herzegovina, Banjaluka, Bosnia and Herzegovina ${ }^{3}$ Public Health Institute of the Republic of Srpska, Department of Social Medicine, Medical Faculty of Banjaluka University, Bosnia and Herzegovina, Banjaluka, Bosnia and Herzegovina

Email: sinisa.vujmilovic@kc-bl.com

How to cite this paper: Vujmilović, S., Vujnović, S., Kovačević-Dragosavljević, V., Vujković, Z., Katana, D. and Grujić-Vujmilović, D. (2016) Patient's Comfort and Technical Quality Exams at 1.5 and 3.0 T Magnetic Resonance Imaging. Open Journal of Radiolo$g y$, 6, 264-274.

http://dx.doi.org/10.4236/ojrad.2016.64035

Received: September 26, 2016

Accepted: October 16, 2016

Published: October 19, 2016

Copyright $\odot 2016$ by authors and Scientific Research Publishing Inc. This work is licensed under the Creative Commons Attribution International License (CC BY 4.0).

http://creativecommons.org/licenses/by/4.0/

\section{Abstract}

Increased interest of clinicians for using 3.0 $\mathrm{T}$ magnetic resonance imaging (MRI), as imaging modality of choice for their patients, has been evident in the past few years. The aim of this study was to compare the technical quality of the obtained tomography using 3.0 $\mathrm{T}$ and 1.5 T MRI, and to compare the subjective feeling of discomfort of patients and subjective acoustic noise experience during imaging using MRI at 3.0 $\mathrm{T}$ and $1.5 \mathrm{~T}$. Brain MRI (1.5 and 3.0 T) was performed in 58 patients, according to a standardized protocol. All studies have been randomly described by independent two radiologists. The reference standard for the existence of technical artifact is established on the basis of both radiologists' consensus. We also compared the subjective feelings of the discomfort and acoustic noise during the both MRI (1.5 $\mathrm{T}$ and $3.0 \mathrm{~T})$ exams. Artifacts were significantly more common during 3.0 T MRI in comparison with the $1.5 \mathrm{~T}$ MRI $\left(\chi^{2}=5.286, \mathrm{P}<0.05\right)$, as well as in male patients $\left(\chi^{2}=8.841, \mathrm{P}<\right.$ $0.05)$, and subjective assessments of discomfort and acoustic noise were higher in patients who underwent imaging using 3.0 T MRI, $\left(\chi^{2}=125.959, \mathrm{df}=1, \mathrm{P}<0.001\right)$ and in females $\left(\chi^{2}=195.449, \mathrm{df}=1, \mathrm{P}<0.001\right)$. Additional research is needed to prove that appropriate information for patients about the discomfort during 3.0 T MRI and their psychological preparation is very important element for optimal use of $3.0 \mathrm{~T}$ MRI in daily clinical practice.

\section{Keywords}

Magnetic Resonance Imaging (MRI), 3.0 T, Artifacts, Acoustic Noise, Discomfort, Comfort 


\section{Introduction}

Magnetic resonance imaging (MRI) is considered to be a safe imaging technique. From the first days of using MRI, there have been a lot of attempts to make scanner with stronger magnetic field [1]. Today, the standard magnetic field strength of MRI is 1.5 Tesla, but the number of 3.0 T MRI installations is increasing. The main advantage for an MR scanner with stronger magnetic field is increased signal to noise ratio (SNR) which enables faster recording at a given resolution, better resolution for a given recording time or a combination of both [2].

Susceptibility artifacts could be useful for detection of hemoglobin breakdown products [3]. The limitation of MR scanners at strong magnetic field is an increase of susceptibility artifacts caused by the magnetic field inhomogeneity, pulsatile artifacts due to flow, artifacts due to chemical shifts, dielectric resonance artifacts [4]. When constructing MRI scanners at strong magnetic field, it is much more difficult to achieve magnetic field homogeneity. Even more is difficult to overcome inhomogeneity resulting from the anatomy of the patient, whose presence disturbs the field homogeneity due to the difference susceptibility of various tissues [5]. This is especially pronounced at the border between tissue and air, and it is seen in the temporal lobe area where the bones and the air filled sinuses are near brain tissue [6].

Good quality examination largely depends on how an individual tolerates lying in the MR scanner, environment and performed procedures. Factors influencing a reduced tolerance patient for all MR scanners independent of magnetic field strength are extended time of scanning, ambient temperature, acoustic noise, uncomfortable position during laying and a personal level of the discomfort [7]. Discomfort in the form of dizziness, weakness, nausea, peripheral nerve stimulation, a sense of metallic taste in the mouth, is more common described in patients who underwent MRI at $3.0 \mathrm{~T}$ and higher than in patients who underwent MRI at $1.5 \mathrm{~T}$ [8]-[10].

The strongest level of noise that was measured during the noisiest sequences at $1.5 \mathrm{~T}$ MRI was $101-117 \mathrm{~dB}$ [11] and at 3.0 T MRI, it was $122-131 \mathrm{~dB}$ [12]. The noise and the closed environment and the ability of tissue heating during MR imaging could worsen anxiety and induce claustrophobia.

Anxiety patients are more likely to experience claustrophobia during MRI, in up to $35 \%$ of cases [13]. Between $1 \%$ and $15 \%$ of patients requiring MR imaging suffer from claustrophobia, and in $2.3 \%$ of cases sedation is required to perform the imaging [14]. It is assumed that because of claustrophobia 2,000,000 MRI yearly could not be performed, or they have to be prematurely terminated, with annual productivity loss of one billion US dollars [15]. Such patients require sedation and additional sequences after sedation to have imaging successfully completed. In some cases, sedation is not sufficient, so it is necessary to introduce the patient in a short-term general anesthesia. In addition to the possible side effects of anesthesia [16] [17] there are also additional costs due to a disrupted and reduced working process (workflow), limited ability of the patient to cooperate and the spent time intended for imaging [18].

The aim of this study was to compare the technical quality of the obtained tomogra- 
phy using 3.0 $\mathrm{T}$ and 1.5 T MRI, and to compare the subjective feeling of discomfort of patients and subjective acoustic noise experience during imaging using MRI at $3.0 \mathrm{~T}$ and $1.5 \mathrm{~T}$.

\section{Materials and Methods}

\subsection{Patients}

The study was conducted as a prospective study from 30 September 2013 to 01 May 2014 in the Department of Clinical Radiology, University Medical Centre in Banja Lu$\mathrm{ka}$. The study included 58 patients suffering from epilepsy older than 6 , both gender.

The study was approved by the Ethics Committee of the Clinical Center of Banja Luka. Before each examination patients were thoroughly informed by the radiologist about examination, duration of the imaging, noise exposure, and confinement. Patients were informed that imaging could be discontinued at any time. All patients gave informed consent to participate in this study. For juvenile patients informed consent for participation in the study was given by parents. Before imaging each patient filled out a security form of the Institute of Clinical Medicine, which was explained to each patient individually. For juvenile patients, the security form was filled out by their parents.

\subsection{Instrumentation and Technique}

Each patient was examined using a MR scanner at $1.5 \mathrm{~T}$ as well as the MR scanner at 3.0 T. The time interval between the two MRIs was not longer than 14 days. Visualizations were performed using 1.5-T MR scanner (Avanto, Siemens, Erlangen, Germany), software version NUMARIS/4 (syngo MR B13) coil Head Matrix Coil (12-element design, IPAT-compatible coil for standard and advanced neuro applications) and 3.0-T MR scanner (GE Signa, General Electric, Milwaukee, WI, USA), software version mRose: GEHCMR_1.1-8_cselx1.1_OS MrpApps: 15.0_M4B_1034.a, coil HD NV Array (8-channel, 12-element phased array design).

Identical, standardized protocol was applied for each MRI. A standardized protocol includes sagittal T1W tomography, T2W, and FLAIR axial tomography parallel to the axis of the temporal lobe, and T2W, FLAIR, STIR/T1 FSPGR tomography in coronal plane and optionally triplane contrast T1W.

Radiologists registered technical artifacts that lead to the degradation of MR images, which were related to the MR scanners and displacement of the patient. The presence of technical artifact radiologists evaluated with "Yes or No". The following was notified: artifacts caused by displacement, movement, artifacts caused by magnetic field distortion, aliasing artifacts, artifacts caused by metal objects, chemical shift artifacts, Gibbs artifacts. All artifacts that were identified by both radiologists were compared with a reference standard. The reference standard for the existence of technical artifact is established on the basis of both radiologists' consensus.

Levels of general discomfort that might have been experienced during both MRI were evaluated and reported by the patients using values of 1 to 10 . Value 1 corresponded to the absence of any discomfort, while a value 10 corresponded to the intoler- 
able discomfort.

Levels of acoustic noise that might have been experienced during the both MRI were evaluated and reported by the patients using scale from 1 to 10 . Value 1 corresponds to the absence of any acoustic noise, until a value 10 corresponds to the state of intolerable acoustic noise. Noise and discomfort evaluation was not correlated with MRI sequences.

Data on the subjective feeling of discomfort and subjective feeling of exposure to noise were entered in the forms created by the author.

\subsection{Statistical Analysis}

Statistical program SPSS for Windows software (SPSS18.0, Inc., Chicago, Illinois, USA) and Microsoft Excel (Microsoft Corporation, Redmond, WA, USA) was used for statistical analysis of the data obtained.

All results will be properly statistically analyzed (descriptive statistics, sensitivity, specificity, appropriate statistical tests with significance level of $\mathrm{P}<0.05)$.

\section{Results}

The study included 58 patients suffering from epilepsy, 30 men (51.7\%) and 28 women $(48.3 \%)$. The average age of patients was $27.6( \pm 14.1)$ with a range of $9-70$ years. Most of patients (33 of them), were 11 to 30 years old (56.9\%). Three patients manifested anxiety and claustrophobia during the first MRI (man and woman at $3.0 \mathrm{~T}$ and man at 1.5 $\mathrm{T}$ ) and withdrawal examinations. They have been excluded from the study.

For 1.5 T MR scanner, radiologists by consensus included 10 MRI exams in the reference standard (interrater agreement coefficient at $1.5 \mathrm{~T}$ was 0.837 ) and for $3.0 \mathrm{~T}$ MRI they included $15 \mathrm{MRI}$ exams, with artifacts that significantly degraded image quality (interrater agreement coefficient at 3-T was 0.828) (Table 1).

The following was evaluated: effects of gender, the strength of MRI and their relations with the number of artifacts by consensus using Brunner-Langer nonparametric ANOVA. The results showed that there was a statistically significant difference in the number of artifacts in men and women $\left(\chi^{2}=8.841, \mathrm{P}<0.05\right)$, as well as a statistically significant difference in the number of artifacts at $1.5 \mathrm{~T}$ and at $3.0 \mathrm{~T}\left(\chi^{2}=5.286, \mathrm{P}<\right.$ $0.05)$. Artifacts were more common in men than women and more common seen at 3.0 $\mathrm{T}$ (Table 2).

There were 11 artifacts in 10 patients at $1.5 \mathrm{~T}$ MRI and 18 artifacts in 15 patients at 3.0 T MRI (Table 3).

It was tested whether the effects of gender and their interaction on the discomfort evaluation (based on consensus) were significant, using Brunner-Langer non-parametric ANOVA. The results showed that there was a statistically significant difference between estimates of discomfort for men and women $\left(\chi^{2}=13.623\right.$, $\left.\mathrm{df}=1, \mathrm{P}<0.001\right)$, average rank of estimates of discomfort for men was 43.583, and for women 63.798 . So, we could conclude that the assessment of discomfort was greater for women than for men (Table 4). 
Table 1. The total number of artifacts, for radiologists and consensus.

\begin{tabular}{|c|c|c|c|c|c|}
\hline & & \multicolumn{4}{|c|}{ Artifacts } \\
\hline & & \multicolumn{2}{|c|}{ Yes } & \multicolumn{2}{|c|}{ No } \\
\hline & & $\mathrm{N}$ & $\%$ & $\mathrm{~N}$ & $\%$ \\
\hline \multirow{2}{*}{ The first radiologist } & $1.5 \mathrm{~T}$ & 11 & 19.0 & 47 & 81.0 \\
\hline & $3.0 \mathrm{~T}$ & 15 & 25.9 & 43 & 74.1 \\
\hline \multirow{2}{*}{ The second radiologist } & $1.5 \mathrm{~T}$ & 12 & 20.7 & 46 & 79.3 \\
\hline & $3.0 \mathrm{~T}$ & 17 & 29.3 & 41 & 70.7 \\
\hline \multirow{4}{*}{ Consensus } & $1.5 \mathrm{~T}$ & 10 & 17.2 & 48 & 82.8 \\
\hline & $3.0 \mathrm{~T}$ & 15 & 25.9 & 43 & 74.1 \\
\hline & \multicolumn{5}{|c|}{ Interrater agreement coefficient for $1.5 \mathrm{~T}$ MRI was 0.837} \\
\hline & \multicolumn{5}{|c|}{ Interrater agreement coefficient for $3 \mathrm{~T}$ MRI was 0.828} \\
\hline
\end{tabular}

Table 2. Number of artifacts in relation to gender and magnetic field strength.

\begin{tabular}{ccc}
\hline \multicolumn{2}{c}{ Number of artifacts } \\
\hline Magnetic field strength & $\mathrm{M}$ & Gender \\
\hline & \multicolumn{2}{c}{$\mathrm{F}$} \\
\hline $3.0 \mathrm{~T}$ & 9 & 1 \\
\hline$\chi^{2}=5.286, \mathrm{P}=0.022$ & & 3 \\
\hline
\end{tabular}

Table 3. Types of artifacts in relation to gender and magnetic field strength.

\begin{tabular}{ccccc}
\hline \multirow{2}{*}{ Artifactscaused by } & \multicolumn{2}{c}{$1.5 \mathrm{~T}$} & \multicolumn{2}{c}{$3.0 \mathrm{~T}$} \\
\cline { 2 - 5 } & men & women & men & women \\
\hline Movement & 4 & 1 & 6 & 2 \\
Distorsion of magnetic field & 2 & 0 & 2 & 1 \\
Metal objects & 2 & 1 & 2 & 1 \\
Other & 1 & 0 & 13 & 5 \\
Total & 9 & 2 & &
\end{tabular}

Table 4. Evaluation of patient's discomfort in relation to gender and magnetic field strength.

Evaluation of patient's discomfort in relation to gender and magnetic field strength

\begin{tabular}{cccc}
\hline & Average rank for discomfort estimates & Brunner-Langer non-parametric ANOVA \\
\hline Gender & M & 43.583 & $\chi^{2}=13.623, \mathrm{P}<0.001$ \\
& $\mathrm{~F}$ & 63.798 & \\
$\begin{array}{c}\text { Magnetic field } \\
\text { strength }\end{array}$ & $1.5 \mathrm{~T}$ & 36.186 & $\chi^{2}=125.959, \mathrm{P}<0.001$ \\
& $3.0 \mathrm{~T}$ & 71.196 & \\
\hline
\end{tabular}


Also, it was tested whether the effects of MR strength and their interaction on the discomfort evaluation (based on consensus) were significant, using Brunner-Langer non-parametric ANOVA. The results showed that there was a statistically significant difference between estimates of discomfort for $1.5 \mathrm{~T}$ and $3.0 \mathrm{~T}$ MRI $\left(\chi^{2}=125.959, \mathrm{df}=\right.$ $1, \mathrm{P}<0.001$ ). Average rank of estimates of discomfort for $1.5 \mathrm{~T}$ MRI was 36.186, and for 3.0 T MRI was 71.196. So, we could conclude that the assessment of discomfort was greater for 3.0 T MRI than for 1.5 T MRI (Table 4).

It was tested whether the effects of gender and their interaction on the patient's evaluation regarding acoustic noise (based on consensus) were significant, using Brunner-Langer non-parametric ANOVA. The results showed that there was a statistically significant difference between estimates of acoustic noise for men and women $\left(\chi^{2}=\right.$ $15.256, \mathrm{df}=1, \mathrm{P}<0.001)$. Average rank of estimates of acoustic noise for men was lower (44.380) in comparison to women (62.971) (Table 5).

Also, it was tested whether the effects of MR strength and their interaction on the patient evaluation of acoustic noise (based on consensus) were significant, using Brunner-Langer non-parametric ANOVA. Average rank of estimates of acoustic noise for 1.5 T MRI was 32.937, and for 3.0 T MRI was 74.413. The results showed that there was a statistically significant difference between estimates of acoustic noise for $1.5 \mathrm{~T}$ and 3.0T MRI $\left(\chi^{2}=195.449, \mathrm{df}=1, \mathrm{P}<0.001\right)$. Average rank of estimates of acoustic noise for 1.5 T MRI was lower (32.937) in comparison to 3.0 T MRI (74.413) (Table 5).

Calculated correlation coefficients (Pearson and Spearman correlation coefficient) are those between the age of patients and, respectively, discomfort and acoustic noise that patients experienced during the MRI at $1.5 \mathrm{~T}$ or at $3.0 \mathrm{~T}$. The correlation coefficients were not significantly different from zero (in all cases, P-value of the test was greater than 0.05). There was no correlation between the age of patients and the discomfort or acoustic noise that patients experienced during the MRI at $1.5 \mathrm{~T}$ or at $3.0 \mathrm{~T}$ (Table 6).

\section{Discussion}

With a statistically significant difference there was greater number of artifacts registered on 3.0 T MR scanner versus 1.5 T MR scanner and they were seen more common in males than in females. The largest number of artifacts are caused by the movement, and then because of magnetic field distortion.

Research by Phal and associates showed that artifacts, due to displacements, were

Table 5. Evaluation of acoustic noise in relation to gender and magnetic field strength.

\begin{tabular}{|c|c|c|c|}
\hline \multicolumn{4}{|c|}{ Evaluation of acoustic noise in relation to gender and magnetic field strength } \\
\hline & \multicolumn{2}{|c|}{ Average rank for discomfort estimates } & Brunner-Langer non-parametric ANOVA \\
\hline \multirow[b]{2}{*}{ Gender } & M & 44.380 & \multirow[b]{2}{*}{$\chi^{2}=15.256, \mathrm{P}<0.001$} \\
\hline & $\mathrm{F}$ & 62.971 & \\
\hline \multirow{2}{*}{$\begin{array}{l}\text { Magnetic field } \\
\text { strength }\end{array}$} & $1.5 \mathrm{~T}$ & 32.937 & \multirow{2}{*}{$\chi^{2}=195.449, \mathrm{P}<0.001$} \\
\hline & $3.0 \mathrm{~T}$ & 74.413 & \\
\hline
\end{tabular}


Table 6. Correlation coefficients for age and acoustic noise and discomfort for $1.5 \mathrm{~T}$ MRI or 3.0 T MRI.

\begin{tabular}{|c|c|c|c|c|c|}
\hline Variable & MR & $\begin{array}{c}\text { Pearson's correlations } \\
\text { coefficient }\end{array}$ & Test statistics & $\begin{array}{c}\text { Spearman rank } \\
\text { correlation coefficient }\end{array}$ & Test statistics \\
\hline \multirow{2}{*}{ Acoustic noise } & $1.5 \mathrm{~T}$ & 0.039 & $\begin{array}{c}\mathrm{t}=0.276 \\
\mathrm{df}=51 \\
\mathrm{P}=0.784\end{array}$ & 0.059 & $\begin{array}{c}\mathrm{t}=0.425 \\
\mathrm{df}=51 \\
\mathrm{P}=0.672\end{array}$ \\
\hline & $3.0 \mathrm{~T}$ & -0.138 & $\begin{array}{c}\mathrm{t}=-0.995 \\
\mathrm{df}=51 \\
\mathrm{P}=0.325\end{array}$ & -0.070 & $\begin{array}{c}\mathrm{t}=-0.501 \\
\mathrm{df}=51 \\
\mathrm{P}=0.618\end{array}$ \\
\hline \multirow{2}{*}{ Discomfort } & $1.5 \mathrm{~T}$ & -0.129 & $\begin{array}{c}t=-0.926 \\
d f=51 \\
P=0.359\end{array}$ & -0.105 & $\begin{array}{c}\mathrm{t}=-0.752 \\
\mathrm{df}=51 \\
\mathrm{P}=0.456\end{array}$ \\
\hline & $3.0 \mathrm{~T}$ & -0.141 & $\begin{array}{c}\mathrm{t}=-1.015 \\
\mathrm{df}=51 \\
\mathrm{P}=0.321\end{array}$ & -0.120 & $\begin{array}{c}\mathrm{t}=-0.861 \\
\mathrm{df}=51 \\
\mathrm{P}=0.393\end{array}$ \\
\hline
\end{tabular}

equally expressed at $1.5 \mathrm{~T}$ and $3.0 \mathrm{~T}$, while other artifacts were significantly lower at 3.0 $\mathrm{T}$ [19]. Mellerio and colleagues noted a smaller number of artifacts registered at $1.5 \mathrm{~T}$ compared to $3.0 \mathrm{~T}$ MRI; they conducted the research analyzing 25 patients with focal cortical dysplasia's type 2 [20]. Artifacts were registered in 5 patients who underwent 3.0 T MRI and in 2 patients who underwent 1.5 T MRI.

In the paper by Zijlmans and associates of the examined 27 patients, artifacts were registered in 1 patient who underwent $1.5 \mathrm{~T}$ MRI due to displacement and in 2 patients who underwent 3.0 T MRI, and one patient was excluded from analysis due to demonstrated artefacts at 3.0 T MRI [21]. Zijmans considers that the institutions in which the 3.0 T MRI is standard, in some cases would repeat exam at 1.5 T MRI where the artifacts in temporal and fronto-basilars regions were less demonstrated. The results of our study do not provide an explanation of why the artifacts are more common in men. More research is needed and different study design.

In our research, the subjective assessment of acoustic noise in patients who underwent 3.0 T MRI is significantly higher compared to patients who underwent MRI at 1.5 $\mathrm{T}$, and subjective assessment of noise is greater in women than in men. Also, the subjective assessment of discomfort on patients who underwent 3.0 T MRI is significantly higher compared to patients who underwent 1.5 T MRI, and subjective assessment of discomfort is greater in women than in men.

Price and colleagues measured the noise of 15 different MR scanners, magnitude 0.2 to 3.0 Tesla [11]. The highest noise level was recorded at 3.0 T MR scanner (118.4 \pm 1.3 $\mathrm{dB}(\mathrm{A})$ ). Similar findings were reported by Hattori and colleagues who have registered a higher level of noise during all sequences on 3.0 T MRI compared to $1.5 \mathrm{~T}$ [12].

In the paper by Chou et al., acoustic noise is the most common cause of discomfort for children and youth who underwent MRI at $3.0 \mathrm{~T} \mathrm{[22].} \mathrm{Up} \mathrm{to} 70 \%$ of children younger than 12 years indicated the noise as a major complaint during the MR imaging. 25\% adults and older children considered that acoustic noise was a problem. 
Less than $20 \%$ of children who underwent 3.0 T MRI complained of general discomfort, feeling cold, claustrophobia, and dizziness. Weintraub and colleagues reported for the 1023 patients who underwent 3.0 T MRI the following: sensory inconvenience in $14 \%$ patients, with dizziness, headaches and low back pain were more common in patient who underwent 3.0 T MRI, and metallic taste in the mouth was more common in patients who underwent 1.5 T MRI [10]. All the symptoms mentioned in the study were more common in females.

Study by Esed and associates revealed that claustrophobia occurred more often in females, with no significant difference [23]. In one study, Berg and colleagues examined the reasons why women with high risk for breast cancer refused breast MRI. Their results showed that even $10.6 \%$ (133 of 1215) patients, in whom breast MRI was indicated, were not examined due to claustrophobia [24] and that claustrophobia was the most common reason for unperformed MRI (25.4\%).

Results of the study conducted by Dawey and associates, which included 55,000 patients who had undergone various MRI examinations, showed that the claustrophobia was statistically more common in women and middle-aged patients [14]. The same author quoted that the incidence of claustrophobia was 1.7 times higher in women (compared to males) and that was 2.1 times more common in middle-aged people.

In our study there was no correlation between the age of patients and the discomfort or acoustic noise that patients experienced during $1.5 \mathrm{~T}$ or $3 \mathrm{~T}$ MRI. One patient at 3.0 T MRI (the second exam) exhibited symptoms of claustrophobia in the middle of the procedure. The exam was completed with additional effort of personnel and few interruptions and pronounced artifacts. Patients which have anxiety and claustrophobia that require sedation and anesthesia have been excluded from the study because they could not objectively estimate, noise and general discomfort.

To avoid claustrophobic reactions of patients, there are attempts to improve comfort during MRI, usually by reducing acoustic noise and reducing feelings of isolation simulating panoramic view [25]. Positive effects of noise reduction by using an improved gantry design (short and long) have been confirmed in a large sample of patients who were examined in the MR scanner with a new cylindrical, CT gantry-like, design with $97 \%$ reduction in acoustic noise [14]. However, patients with claustrophobia often have to receive potentially risky sedation or anesthesia, even if they are undergoing improved MRI.

MR scanner with an open gantry is useful for anxious patients. Until recently, their main disadvantage was the low field $(0.2 \mathrm{~T})$, which resulted in poor quality imaging. [26]. Diagnostic value of recently produced "open" high field MRI scanners (1.0 T) is yet to be confirmed [27]. Technologies that enable MR sequences with low levels of noise are increasingly used, and a special attention is paid to their further development [28]-[30].

\section{Conclusions}

In the past few years, increased interest of clinicians for using 3.0 T MR scanner as imaging modality for their patients is evident. The reason is a superior spatial and tem- 
poral resolution and better signal to noise ratio compared to $1.5 \mathrm{~T}$ MRI. On the other hand, clinical practice shows that the success of MRI depends not only on the abovementioned parameters, but also on a whole range of other parameters that are related to scanner, staff and patients.

Our results showed that artifacts were significantly more common during 3.0 T MRI in comparison with the 1.5 T MRI, as well as in male patients, and subjective assessments of discomfort and acoustic noise were higher in patients who underwent $3.0 \mathrm{~T}$ MRI, and in females. Appropriate information for patients about discomfort during 3.0 T MRI, and their psychological preparation is very important element for optimal use of 3.0 T MRI in daily clinical practice. The future will probably show new technological solutions that will reduce the feeling of discomfort and noise and thus contribute to quality imaging.

\section{References}

[1] Blamire, A.M. (2008) The Technology of MRI-The Next 10 Years? British Journal of Radiology, 81, 601-617. http://dx.doi.org/10.1259/bjr/96872829

[2] Kuhl, C.K., Träber, F. and Schild, H.H. (2008) Whole-Body High-Field-Strength [3.0-T] MR Imaging in Clinical Practice. Part I. Technical Considerations and Clinical Applications. Radiology, 246, 3, 675-696. http://dx.doi.org/10.1148/radiol.2463060881

[3] Mittal, S., Wu, Z., Neelavalli, J. and Haacke, E.M. (2009) Susceptibility-Weighted Imaging: Technical Aspects and Clinical Applications, Part 2. AJNR American Journal of Neuroradiology, 30, 232-252. http://dx.doi.org/10.3174/ajnr.A1461

[4] Bernstein, M.A., Huston, J. and Ward, H.A. (2006) Imaging Artifacts at 3.0T. Journal of Magnetic Resonance Imaging, 24, 735-746. http://dx.doi.org/10.1002/jmri.20698

[5] Morelli, J.N., Runge, V.M., Ai, F., Attenberger, U., Vu, L., Schmeets, S.H., Nitz, W.R. and Kirsch, J.E. (2011) An Image-Based Approach to Understanding the Physics of MR Artifacts. Radiographics, 31, 849-866. http://dx.doi.org/10.1148/rg.313105115

[6] Briellman, R.S., Pell, G.S., Wellard, R.M., Mitchell, L.A., Abbott, D.F. and Jackson, G.D. (2003) MR Imaging of Epilepsy: State of the Art at 1.5 T and Potential of 3 T. Epileptic Disord, 5, 3-20.

[7] Haddad, A.D., Platt, B., James, A.C., et al. (2013) Anxious and Non-Anxious Adolescents' Experiences of Non-Clinical Magnetic Resonance Imaging Research. Child Psychiatry \& Human Development, 44, 556-560. http://dx.doi.org/10.1007/s10578-012-0350-x

[8] Cavin, I.D., Glover, P.M., Bowtell, R.W., et al. (2007) Thresholds for Perceiving Metallic Taste at High Magnetic Field. Journal of Magnetic Resonance Imaging, 26, 1357-1361. http://dx.doi.org/10.1002/jmri.21153

[9] Glover, P.M., Cavin, I., Qian, W., et al. (2007) Magnetic-Field-Induced Vertigo: A Theoretical and Experimental Investigation. Bioelectromagnetics, 28, 349-361. http://dx.doi.org/10.1002/bem.20316

[10] Weintraub, M.I., Khoury, A. and Cole, S.P. (2007) Biologic Effects of 3 Tesla (T) MR Imaging Comparing Traditional $1.5 \mathrm{~T}$ and $0.6 \mathrm{~T}$ in 1023 Consecutive Outpatients. Journal of Neuroimaging, 17, 241-245. http://dx.doi.org/10.1111/j.1552-6569.2007.00118.x

[11] Price, D.L., De Wilde, J.P., Papadaki, A.M., et al. (2001) Investigation of Acoustic Noise on 15 MRI Scanners from 0.2T to 3T. Journal of Magnetic Resonance Imaging, 13, 288-293. http://dx.doi.org/10.1002/1522-2586(200102)13:2<288::AID-JMRI1041>3.0.CO;2-P 
[12] Hattori, Y., Fukatsu, H. and Ishigaki, T. (2007) Measurement and Evaluation of the Acoustic Noise of a 3 Tesla MR scanner. Nagoya Journal of Medical Science, 69, 23-28.

[13] Brennan, S.C., Redd, W.H., Jacobsen, P.B., Schorr, O., Heelan, R.T., Sze, G.K., Krol, G., Peters, B.E. and Morrissey, J.K. (1988) Anxiety and Panic during Magnetic Resonance Scans. Lancet, 2, 512. http://dx.doi.org/10.1016/S0140-6736(88)90159-6

[14] Dewey, M., Schink, T. and Dewey, C.F. (2007) Claustrophobia during Magnetic Resonance Imaging: Cohort Study in over 55,000 Patients. Journal of Magnetic Resonance Imaging, 26, 1322-1327. http://dx.doi.org/10.1002/jmri.21147

[15] Enders, J., Zimmermann, E., Rief, M., Martus, P., Klingebiel, R., Asbach, P., Klessen, C., Diederichs, G., Bengner, T., Teichgräber, U., Hamm, B. and Dewey, M. (2011) Reduction of Claustrophobia during Magnetic Resonance Imaging: Methods and Design of the “CLAUSTRO” Randomized Controlled Trial. BMC Medical Imaging, 11, 4. http://dx.doi.org/10.1186/1471-2342-11-4

[16] Bluemke, D.A. and Breiter, S.N. (2000) Sedation Procedures in MR Imaging: Safety, Effectiveness, and Nursing Effect on Examinations. Radiology, 216, 645-652. http://dx.doi.org/10.1148/radiology.216.3.r00se45645

[17] Malviya, S., Voepel-Lewis, T., Eldevik, O.P., Rockwell, D.T., Wong, J.H. and Tait, A.R. (2000) Sedation and General Anaesthesia in Children Undergoing MRI and CT: Adverse Events and Outcomes. British Journal of Anaesthesia, 84, 743-748. http://dx.doi.org/10.1093/oxfordjournals.bja.a013586

[18] Berlin, L. (2001) Sedation and Analgesia in MR Imaging. AJR American Journal of Roentgenology, 177, 293-296. http://dx.doi.org/10.2214/ajr.177.2.1770293

[19] Phal, P.M., Usmanov, A., Nesbit, G., Anderson, J.C., Spencer, D., Wang, P., et al. (2008) Qualitative Comparison of 3-T and 1.5-T MRI in the Evaluation of Epilepsy. $A J R, 191$, 890-895. http://dx.doi.org/10.2214/AJR.07.3933

[20] Mellerio, C., Labeyrie, M.A., Chassoux, F., Roca, P., Alami, O., Plat, M., Naggara, O., Devaux, B., Meder, J.F. and Oppenheim, C. (2014) 3T MRI Improves the Detection of Transmantle Sign in Type 2 Focal Cortical Dysplasia. Epilepsia, 55, 117-122. http://dx.doi.org/10.1111/epi.12464

[21] Zijlmans, M., de Kort, G.A.P., Witkamp, T.D., Huiskamp, G.M., Seppenwoolde, J.H., van Huffelen, A.C. and Leijten, F.S.S. (2009) 3T versus 1.5T Phased-Array MRI in the Presurgical Work-Up of Patients with Partial Epilepsy of Uncertain Focus. Journal of Magnetic Resonance Imaging, 30, 256-262. http://dx.doi.org/10.1002/jmri.21811

[22] Chou, I.J., Tench, C.R., Gowland, P., Jaspan, T., Dineen, R.A., Evangelou, N., Abdel-Fahim, R., Whitehouse, W.P. and Constantinescu, C.S. (2014) Subjective Discomfort in Children Receiving 3 T MRI and Experienced Adults' Perspective on Children's Tolerability of 7 T: a Cross-Sectional Questionnaire Survey. BMJ Open, 4, e006094. http://dx.doi.org/10.1136/bmjopen-2014-006094

[23] Eshed, I., Althoff, C., EHamm, B. and Hermann, K.G. (2007) Claustrophobia and Premature Termination of Magnetic Resonance Iimaging Examinations. Journal of Magnetic Resonance Imaging, 26, 401-404. http://dx.doi.org/10.1002/jmri.21012

[24] Berg, W.A., Blume, J.D., Adams, A.M., et al. (2010) Reasons Women at Elevated Risk of Breast Cancer Refuse Breast MR Imaging Screening: ACRIN 6666. Radiology, 254, 79-87. http://dx.doi.org/10.1148/radiol.2541090953

[25] Katz, R.C., Wilson, L. and Frazer, N. (1994) Anxiety and Its Determinants in Patients Undergoing Magnetic Resonance Imaging. Journal of Behavior Therapy and Experimental Psychiatry, 25, 131-134. http://dx.doi.org/10.1016/0005-7916(94)90005-1

[26] Merl, T., Scholz, M., Gerhardt, P., Langer, M., Laubenberger, J., Weiss, H.D., Gehl, H.B., 
Wolf, K.J. and Ohnesorge, I. (1999) Results of a Prospective Multicenter Study for Evaluation of the Diagnostic Quality of an Open Whole-Body Low-Field MRI Unit: A Comparison with High-Field MRI Measured by the Applicable Gold Standard. European Journal of Radiology, 30, 43-53. http://dx.doi.org/10.1016/S0720-048X(98)00134-X

[27] Bangard, C., Paszek, J., Berg, F., Eyl, G., Kessler, J., Lackner, K. and Gossmann, A. (2007) MR Imaging of Claustrophobic Patients in an Open 1.0T Scanner: Motion Artifacts and Patient Acceptability Compared with Closed Bore Magnets. European Journal of Radiology, 64, 152-157. http://dx.doi.org/10.1016/j.ejrad.2007.02.012

[28] Alibek, S., Vogel, M., Sun, W., Winkler, D., Baker, C.A., Burke, M. and Gloger, H. (2014) Acoustic Noise Reduction in MRI Using Silent Scan: An Initial Experience. Diagnostic and Interventional Radiology, 20, 360-363. http://dx.doi.org/10.5152/dir.2014.13458

[29] Heismann, B., Ott, M. and Grodzki, D. (2015) Sequence-Based Acoustic Noise Reduction of Clinical MRI Scans. Magnetic Resonance in Medicine, 73, 1104-1109. http://dx.doi.org/10.1002/mrm.25229

[30] Segbers, M., RizzoSierra, C.V., Duifhuis, H. and Hoogduin, J.M. (2010) Shaping and Timing Gradient Pulses to Reduce MRI Acoustic Noise. Magnetic Resonance in Medicine, 64, 546-553.

Submit or recommend next manuscript to SCIRP and we will provide best service for you:

Accepting pre-submission inquiries through Email, Facebook, LinkedIn, Twitter, etc.

A wide selection of journals (inclusive of 9 subjects, more than 200 journals)

Providing 24-hour high-quality service

User-friendly online submission system

Fair and swift peer-review system

Efficient typesetting and proofreading procedure

Display of the result of downloads and visits, as well as the number of cited articles

Maximum dissemination of your research work

Submit your manuscript at: http://papersubmission.scirp.org/

Or contact ojrad@scirp.org 